\title{
SILVA, CIDINHA (ORG).AFRICANIDADESE RELAÇÕES RACIAIS: INSUMOS PARA POLIITICAS PÚBLICAS NA ÁREA DO LIVRO, LEITURA E BIBLIOTECAS NO BRASIL. BRASÍLIA: FUNDAÇÃO CULTURAL PALMARES, 2014.
}

\author{
MaURícIo Silva'
}

Há muito tempo que o tema das relações étnico-raciais na sociedade brasileira deixou de ser uma novidade, ganhando ainda maior importância a partir da década de 1980, com a promulgação da Constituição, e dos anos 2000, especialmente com a lei 10.639. A "novidade" acerca desse assunto, portanto, fica mesmo por conta dos inúmeros desdobramentos que esse tema conheceu presentemente, num conjunto de práticas, teorias e metodologias, em áreas que vão da literatura afro-brasileira às bibliotecas comunitárias, das práticas de leitura às editoras alternativas, passando por experiências escolares e de outra natureza.

O livro Africanidades e relações raciais: insumos para políticas públicas na área do livro, leitura e bibliotecas no Brasil (2014), organizado pela já conhecida escritora e militante Cidinha da Silva, é um exemplo dessa versatilidade temática. Composto por diversos textos, que vão de testemunhos a artigos acadêmicos, apresenta um largo painel das questões étnico-raciais no Brasil, sobretudo, como o título do livro sugere, relacionadas à leitura e à literatura, alguns dos quais passamos a resenhar aqui.

Em "Literatura Negra e Literatura Marginal-Periférica: sobre interseções e fraturas", por exemplo, Mário Augusto Medeiros da Silva começa confirmando a existência tanto da Literatura Negra quanto da Literatura Marginal-Periférica,

1 Professor de Mestrado e Doutorado na Universidade Nove de Julho. Doutor em Letras Clássicas e Vernáculas pela Universidade de São Paulo. 
embora não haja consenso, mesmo entre os que defendem sua existência, acerca de suas definições. A existência de escritores negros na literatura brasileira, segundo o autor, remonta aos séculos XVIII e XIX, embora não se possa falar, então, de literatura negra brasileira, já que seus autores não reivindicaram esse título, o que desloca sua existência para a segunda metade do século XX. Nesse contexto, romancistas como Machado de Assis e Lima Barreto passam a ser considerados escritores fundantes da vertente negra da literatura brasileira, cânone que pode ser complementado com nomes como os de Lino Guedes e Solano Trindade, distintos de autores próprios dessa literatura. Esta, portanto, assume uma configuração própria com autores que, sobretudo a partir das décadas de 1960-1970, assumem produzir uma estética literária negra, vertente que tem na passagem da personagem negra para o autor negro um fato simbólico, num debate que se adensa ao longo da década de 1980 e se torna mais complexo com a ocorrência da Literatura Marginal, a partir da década de 1990. Há, ainda segundo o autor, pelo menos três fatores que aproximam ambas as manifestações literárias (Literatura Negra e Literatura Marginal-Periférica): a existência de autores auto editados nas periferias urbanas brasileiras; a relação entre Ciências Sociais e Literatura; o debate em torno do que seria as marcas de seus autores e dos dois movimentos. Também os autores marginais-periféricos criaram, a exemplo dos autores negros, seus cânones fundantes, como Plínio Marcos, João Antônio, Maria Carolina de Jesus e, mais recentemente, Paulo Lins. Os dois últimos, embora negros, nunca reivindicaram essa categorização. Assim, para Mário Augusto Medeiros da Silva, é possível pensar em conexões entre as duas vertentes literárias, a partir da junção entre o negro e o periférico em um "único sujeito social" (SILVA, 2014, p. 62), embora haja uma reconhecida dificuldade na criação e realização de projetos coletivos comuns.

Em "Por que precisamos de escritoras e escritores negros?", Regina Dalcastagnè lembra que a voz que a literatura apresenta é a voz de seus escritores, que ocupam uma posição central no sistema literário. No caso do Brasil, esse grupo é bastante homogêneo, formado majoritariamente por brancos: "se a literatura brasileira contribuiu historicamente para formar a identidade da nação brasileira, contribuiu seguramente para embranquecê-la" (SILVA, 2014, p. 67). Embora a situação tenha se alterado atualmente, não mudou muito, pois aquilo que é valorizado como literatura ainda é feito, principalmente, por homens, com ensino superior, residindo entre o Rio e São Paulo e brancos. Pesquisas compro- 
vam que, de 1990 até hoje, menos de $5 \%$ dos autores brasileiros são negros ou pardos. Essa homogeneidade em relação aos escritores estende-se para suas personagens, majoritariamente brancas, daí, segundo a autora, a necessidade de escritoras e escritores negros, pois "são eles que trazem para dentro de nossa literatura outra perspectiva, outras experiências de vida, outra dicção" (SILVA, 2014, p. 68).

Em "Meu pai não montava a cavalo nem ia para o campo: algumas questões sobre a formação da escritora e do escritor negro no Brasil contemporâneo", Lívia Natália, a partir de uma breve mirada nas representações da infância dos escritores, sobretudo os poetas, afirma que raramente se encontram autores e autoras negros relatando sua infância, no que concerne à formação leitora. Isso ocorre, segundo ela, em razão de a infância negra ser minorada e esvaziada, por um lado, ou identificada com malandros e marginais, por outro. Assim, o que se percebe é, com raras exceções, a perpetuação de estereótipos. Lívia Natália critica o fato de que poucos autores e autoras utilizam-se da literatura como modo de resistência política, além de lamentar a jovem geração de escritores negros e negras que "padecem de um vazio de representação nas cenas escolares" (SILVA, 2014, p. 79), embora encontrem recursos nos saraus e concursos literários, além das redes sociais. Trata-se de uma geração de escritores/as cuja formação se dá, em muitos casos, "fora do contexto escolar, mas de maneira potente, quase intuitiva e automática, fora dos livros, quase sempre, mas dentro da vida, na vivacidade da rede da internet" (SILVA, 2014, p. 79).

Em "Cânone literário 'sob rasura': a urgência de políticas públicas para publicação/divulgação/circulação das literaturas negro-brasileira e periférica", Fernanda Felisberto e Ricaro 'Riso' discutem a literatura negro-brasileira e o mercado de livro no país, lembrando que "a literatura reproduz as desigualdades sociais e raciais do Brasil" (SILVA, 2014, p. 109). Esse fato tem repercussões no próprio cânone literário nacional, no sentido de que ele "costuma mascarar a manipulação ideológica e o seu caráter de dominação com o intuito de não ser reconhecido" (SILVA, 2014, p. 111). Os autores criticam, nesse contexto, o fato de escritores da literatura negro-brasileiros serem catalogados como africanos, lembrando que muitos africanos não discutem em sua obra questões pertinentes à lei 10639, nem dialogam com a rasura que a literatura negro-brasileira promove no cânone literário nacional. Diante desse quadro, os autores consideram imprescindível "a abertura de outras vozes que tensionam o que é ou deve ser 
literatura" SILVA, 2014, (p. 116), a fim de desestabilizar um cânone que "ilustra uma sociedade seguidora dos padrões europeus" (SILVA, 2014, p. 117). Fazem-se necessárias, por fim, políticas públicas que incentivem a produção editorial de autores negro-brasileiros e periféricos, já que "não há melhor espaço e que atue diretamente na subjetividade das pessoas que a literatura, e somente com o acesso a livros de diferentes grupos subalternizados, como os representantes da literatura negro-brasileira, estaremos alimentando o debate com a troca de pontos de vista e de experiências em uma sociedade plurirracial, porém desigual" (SILVA, 2014, p. 119).

Em "escritores negros: além da recepção convencional", Ronald Augusto discute a resistência ao conceito de literatura negra, lembrando tratar-se de uma contradição, uma vez que o senso comum tende a admirar as manifestações literárias calcadas na realidade, como é comum acontecer com aquele tipo de literatura. Apesar disso, o autor se propõe a discutir os limites e as virtudes da literatura negra, lembrando que ver nela o "testemunho de verdade racial" (SILVA, 2014, p. 204) é, muitas vezes, deixar de lado aspectos estéticos próprios da linguagem literária. Em outros termos, corre-se o risco de se desconsiderar o termo literatura, em prol do adjetivo negra, esquecendo que a expressão literária opera fundamentalmente no campo da linguagem, motivo pelo qual o autor afirma: "antes de qualquer coisa, literatura negra só pode ser mesmo literatura, isto é, uma forma de discurso que tem sua autonomia conectada ao campo estético" (SILVA, 2014, p. 207). Portanto, completa, não se deve assentar essa discussão na ideia de uma produção literária que se baseia na "busca programática de um eu enunciador que se assume negro no tecido da linguagem" (SILVA, 2014, p. 208).

Em "Literatura 'Rapentista”", Marcos Fabrício Lopes da Silva trata do rap no Brasil, esse "recitativo musical originário de encruzilhadas existenciais vivenciadas e projetadas pela afroperspectiva dialógica" (SILVA, 2014, p. 230), destacando, por um lado, seu aspecto como um "combativo protesto político e social" (SILVA, 2014, p. 230) e, por outro lado, sua "linha criativa" (SILVA, 2014, p. 230). $\mathrm{O}$ autor destaca ainda a possibilidade de alinhar o rap e o repente, além de, neste artigo, enfatizar a produção dos rappers-escritores, aqueles que optaram pelo livro, instaurando uma afrografia e compreendendo a literatura sob o enfoque da oratura. Desse contexto, afirma o autor, ressalta-se "o papel da oralidade como traço constitutivo da textualidade africana e afrodescendente" (SILVA, 
2014 , p. 231). Como exemplo da prática aqui exposta, o autor chama a atenção para o livro Poucas Palavras, do rapentista Renan Inquérito.

Em "Literatura periférica e o flerte com a comunicação: tá tudo dominado?", Márcia Maria Cruz se propõe refletir acerca da cobertura dos cadernos de cultura em relação à literatura periférica, entendendo-a "como uma ideia de empoderamento e também como um processo comunicacional" (SILVA, 2014, p. 281). Para a autora, os escritores que representam a literatura periférica promovem uma série de deslocamentos, como o deslocamento de linguagem, ao assumir a oralidade; e contestações, como a contestação ao modelo de mercado editorial predominante. Destaca, nesse contexto, o papel desempenhado pelos saraus: "nos saraus, muitos autores da literatura periférica são incorporados e ressignificados. São apresentados à juventude pobre e trabalhadora, mas em outra perspectiva. Não há uma relação hierárquica e transmissiva, como em geral a literatura é apresentada nos bancos escolares. Ao propor deslocamentos, os saraus chamam atenção para si" (SILVA, 2014, p. 285). E conclui: "A literatura periférica não é uma literatura comercial, no sentido de que sua razão primeira é a venda de exemplares das obras. Trata-se, sobretudo, de um espaço formativo, mas que, obviamente, não prescinde de expandir o número de leitores e interlocutores" (SILVA, 2014, p. 288).

Por esses e outros motivos, os textos que compõem o livro organizado por Cidinha da Silva, Africanidades e relações étnico-raciais, é leitura obrigatória para quem quiser se aventurar no intrincado - e valioso! - mundo das letras no contexto das relações étnico-raciais brasileiras. 